\title{
46. INTEGRATION OF SFL AND ILD ELECTRICAL RESISTIVITY LOGS DURING LEG 133: AN AUTOMATIC MODELING APPROACH ${ }^{1}$
}

\author{
Peter D. Jackson ${ }^{2}$ and Richard D. Jarrard ${ }^{3}$
}

\begin{abstract}
An automatic technique is developed for integrating two electrical resistivity logs obtained during Leg 133 , namely, the deep induction $\log$ (ILD) and the spherically focussed $\log$ (SFL). These logs are routinely run by the Ocean Drilling Program in lower resistivity sedimentary environments, where drilling through soft, poorly consolidated lithologies often results in variable hole diameters. Examples are given to show the superior resolution of the SFL, compared to the ILD, in lithologies encountered during Leg 133, but also the degradation of the SFL response caused by variable hole conditions. A forward modeling program is used to calculate the ILD response, and a corrective scheme is developed that uses the SFL log as the starting point of an "iterative-corrective" procedure that uses, in effect, the ILD log to correct the SFL log for degradation caused by changes in the diameter of the borehole. The calculated induction log (using the corrected SFL log as the input model) is shown to be near to the ILD measured downhole. The authors consider this to be proof that the corrected SFL is a better estimate of the formation resistivity downhole $(\mathrm{Rt})$ than either the SFL or ILD taken alone. Corrections are shown to be substantial in poor hole conditions, and examples are given where geological cyclicity might be confused with hole effects if uncorrected logs were to be used. Corrected SFL logs are shown to combine the high resolution of the SFL with the greater depth of investigation of the ILD. The technique is shown to improve the results of resistivity logging during Leg 133 in thin layers and to have applications when identifying paleoclimatic signals (e.g., in intervals having high sedimentation rates) and in diagenetically altered reefal carbonates where dissolution and cementation caused by changes in sea level may have produced thin layers with contrasting resistivities.
\end{abstract}

\section{INTRODUCTION}

A large number of resistivity logging sondes are in use for logging oil reservoirs, ODP holes, groundwater wells, and geotechnical site investigation boreholes. Electrical surveying in drill holes was invented almost $60 \mathrm{yr}$ ago by Schlumberger et al. (1934). The results were applied successfully by Archie (1942) to predict the porosity and/or water saturation of oil reservoirs. Electrical resistivity logging became widely used in the oil industry as it was used as an important input for predicting of oil reserves. Major advances were made in the early 1950 s by the Schlumberger Corporation with the development of the focused galvanically coupled arrays (Doll, 1951), and inductively coupled resistivity logging techniques (Doll, 1950; 1953). Today resistivity devices are available that allow assessments over a range of both depths of investigation and resolutions.

The vertical resolution and depth of investigation for the resistivity devices used during Leg 133 are shown in Figure 1. The "micro" resistivity imaging device (FMS) has a depth of investigation of less than 1 in. and a resolution of 0.2 in The "macro" resistivity devices (SFL and ILD) have depths of investigation ranging from 25 in. (SFL) to $I 50 \mathrm{in}$. (ILD) and resolutions of $30 \mathrm{in}$. (SFL) and $60 \mathrm{in}$. (ILD). The depth of investigation of the deep induction $\log$ (ILD) is controlled by the resistivity of the formation, being lower in low resistivities. Figure 1 shows that a gap exists in both resolution and depth of investigation between the FMS and SFL (factors of 100 and 20 approx. respectively), indicating there may be difficulty in relating FMS images to SFL and ILD resistivity logs in environments other than those with layering normal to the wellbore.

\footnotetext{
'McKenzie, J.A., Davies, P.J., Palmer-Julson, A., et al., 1993.Proc. ODP, Sci. Results, 133: College Station, TX (Ocean Drilling Program).

${ }_{2}^{2}$ British Geological Survey, Keyworth, Nottingham, NG12 5GG, United Kingdom.

${ }^{3}$ Department of Geology and Geophysics, University of Utah, Salt Lake City, UT 84112 , U.S.A.
}

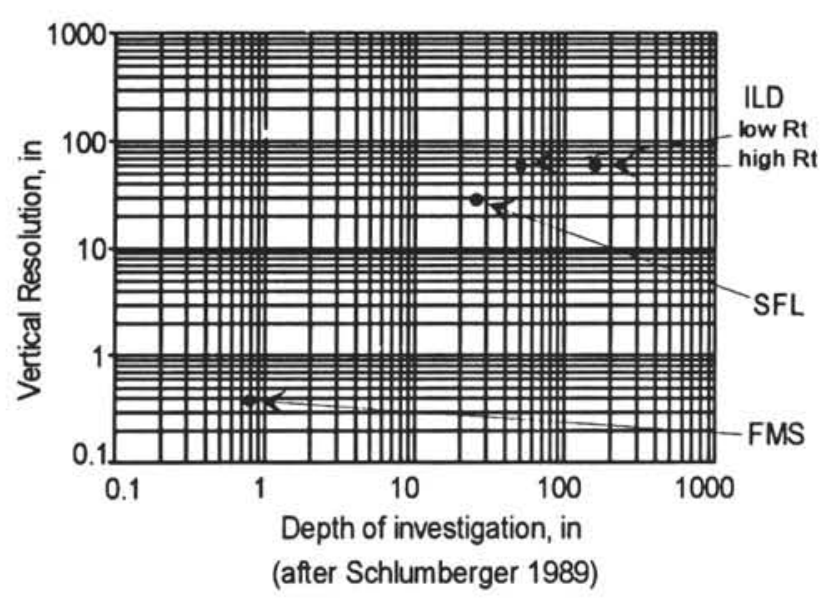

Figure 1. Vertical resolution and depth of investigation for resistivity tools used on Leg 133 of ODP (Standen, 1991).

\section{Resistivity Logging in Sedimentary Formations During Leg 133}

The Schlumberger Corporation has been the sole logging contractor for the Ocean Drilling Program and operates the SFL array in conjunction with induction logging tools (ILM, ILD) in low resistivity environments (usually soft sedimentary formations), and the dual laterolog array (focused, galvanically coupled) in high resistivity environments, which tend to be hard rock. The borehole fluid was sea water in the holes drilled during Leg 133 . The depth of investigation of galvanically coupled focused arrays is controlled by the overall size of the array (Ajam, 1978), which enables on to measure at the same resolution, but at different depths of investigation into the formation. The SFL and dual laterolog are capable of such a measurement scheme; however, they are not normally run together at soft rock sites for the ODP as the low resistivities experienced can be measured more accurately by induction logging (ILD, ILM). 

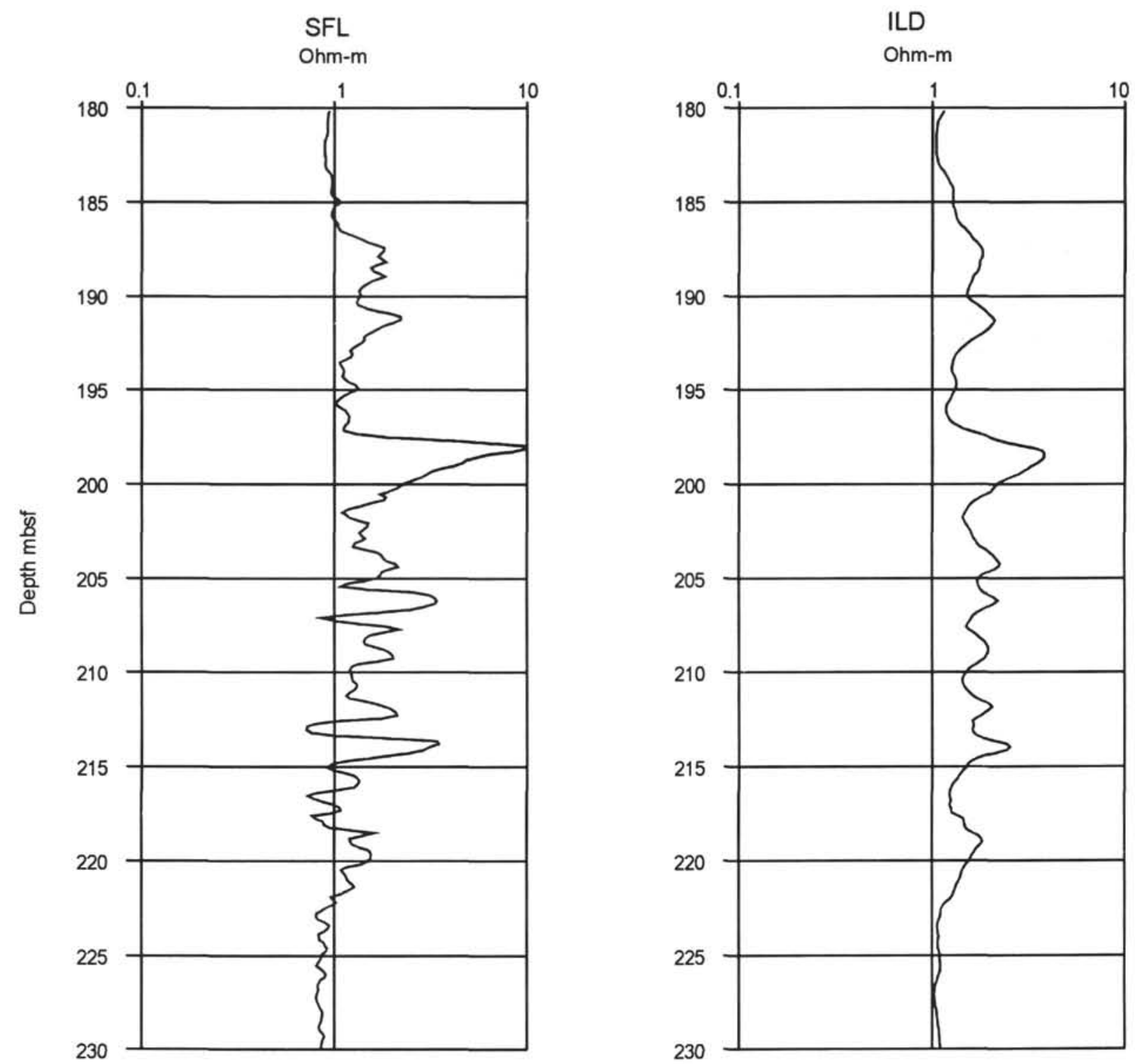

Figure 2. Effect of thin layers at Site 812 on the SFL and ILD resistivity logs operated by ODP at soft rock sites.

A problem arises at soft rock sites for the ODP, where sequences of thin layers have contrasting resistivities that are of scientific interest. The SFL (Schuster et al., 1971), while having higher resolution than the induction logs, is designed to compensate for borehole effects while still maintaining a shallow depth of investigation (25 in. see Fig. 1). Hole enlargement was a significant factor during Leg 133 at soft rock sites, and adversely affected the SFL (i.e., degrading the highest "macro" resolution available to the scientists).

On the other hand, the induction resistivity (ILD) log, is less sensitive to hole enlargement in formations having a low resistivity. For example, using the ILD borehole correction chart (Schlumberger, 1977) and given the following conditions: (1) borehole fluid resistivity $=0.25 \mathrm{ohm}-\mathrm{m} ;(2)$ sediment resistivity $=2.5 \mathrm{ohm}-\mathrm{m}$; (3) hole size $=16$ in.; (4) hole contribution $=12 \mathrm{~m} \mathrm{~S} / \mathrm{m}$; (5) sediment conductivity $=400 \mathrm{~m} \mathrm{~S} / \mathrm{m}$, the borehole contribution, even for a 16-in.-diameter hole, is approximately $3 \%$ of the measured value and cannot be resolved on standard logging displays. In higher resistivity environments the contribution due to the borehole fluid is significant (e.g., over $50 \%$ for a formation resistivity of $100 \mathrm{ohm}-\mathrm{m}$ ).

At soft rock sites having high sedimentation rates, paleoclimatic changes have been suggested as the forcing mechanism for "thin layer" responses seen in the resistivity and sonic logs (Leg 105, Jarrard and Arthur, 1989). Higher resolution and more accurate logs will be required for similar investigations at sites having lower sedimentation rates.

Diagenesis within shallow-water carbonate platforms can produce thin layer responses in resistivity logs, as shown from Site 812 in Figure 2. Site 812 is located on the southern margin of the Queensland Plateau, where shallow-water carbonates were identified below $140 \mathrm{mbsf}$ that had undergone freshwater diagenesis and subaerial exposure (Davies, McKenzie, Palmer-Julson et al., 1991). The resistivity responses between 180 to 230 mbsf shown in Figure 2 illustrate the higher resolution of the shallow penetrating device (SFL) compared to the deep penetrating device (ILD). There are instances where thin layer responses seen in the SFL are not present in the ILD response (e.g., $217 \mathrm{mbsf}$ ).

A further example of thin layering is shown in Figure 3 at Site 815, which is situated along the southern margin of the Townsville Trough, about $3 \mathrm{~km}$ north and in front of the Marion Plateau in a water depth of $465 \mathrm{~m}$. The sediments down to a depth of $416 \mathrm{mbsf}$ were deposited in a hemipelagic environment and are of Pliocene to Pleistocene age. A portion of the log responses for the Pliocene sediment package situated between 100 and $300 \mathrm{mbsf}$ is shown in Figure 3. There has 

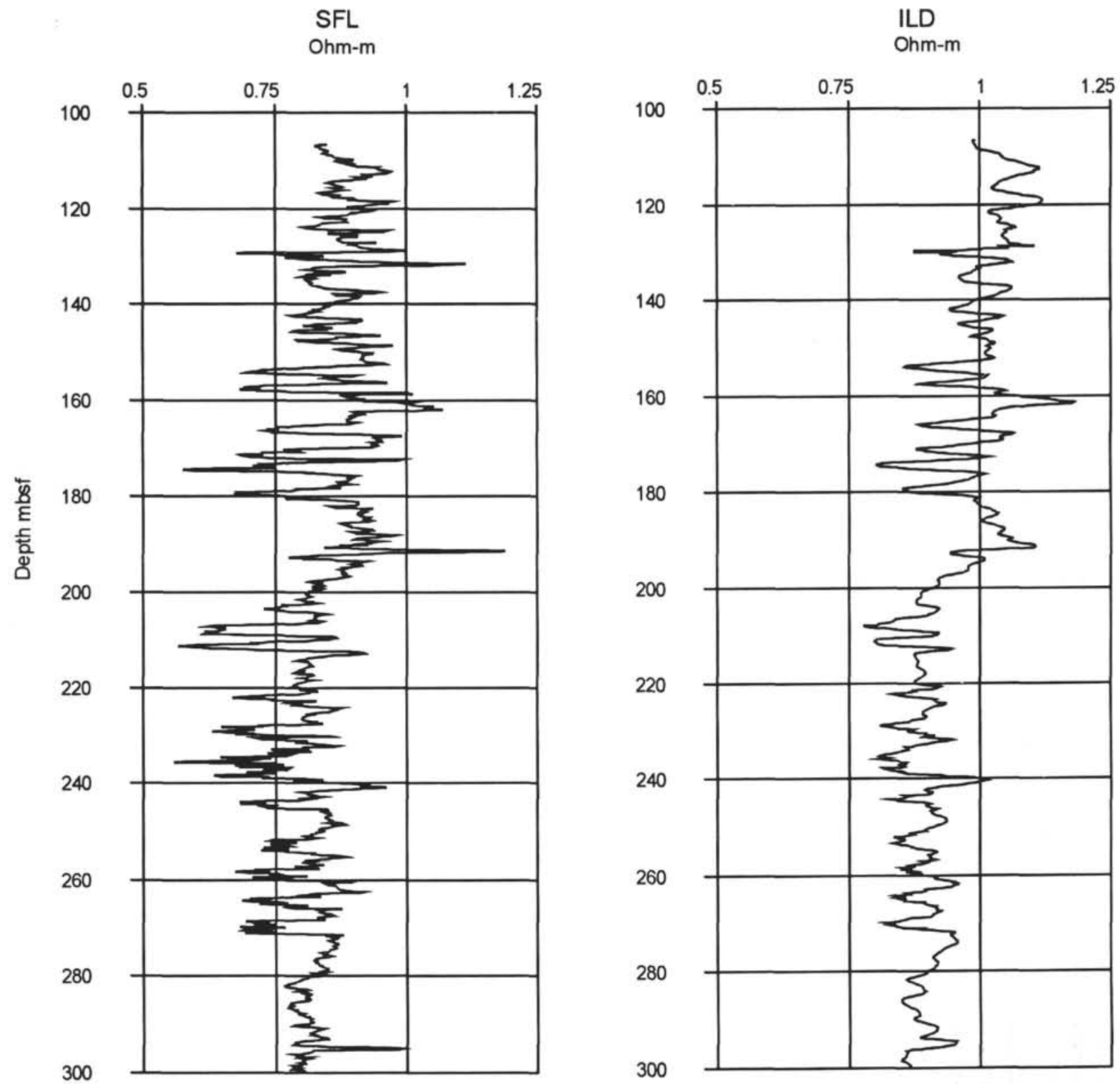

Figure 3. Resistivity logs from Site 815 showing the responses of the SFL and ILD logs to very thin layers in an expanded section.

been very high sedimentation within this unit, with rates of $38 \mathrm{~cm} / \mathrm{k} . y$,, which indicate an expanded section that offers great potential for studying possible Milankovitch control (Davies, McKenzie, PalmerJulson, et al., 1991). However, again substantial differences occur between the resistivity logs (SFL, ILD), with the SFL showing responses that indicate that the layers are thinner than the vertical resolution of the ILD device, furthermore there are indications of beds that are thinner than the resolution of the SFL ( 30 in.).

Thus, an urgent need is to integrate such logs to produce a single resistivity log to estimate the in-situ resistivity in environments having thin layers of differing electrical resistivity.

\section{CORRECTIVE MODELING OF LEG 133 RESISTIVITY LOGS}

Of the resistivity logs run during Leg 133, the ILD was the least affected by poor hole conditions, as a result, the authors decided to seek a way of generating a thin layer model that could be used to calculate a synthetic ILD response. The rationale adopted was to take the model to be an estimate of the resistivity downhole when the calculated ILD response is in agreement with that measured downhole. The authors assume near borehole effects (e.g., invasion) are negligible, and accept that their interpretations may not be unique.

We used an ILD forward modeling program, developed by Hardman and based on published theory (Hardman and Shen, 1986; 1987); to calculate the ILD response from an input model (in the form of a $\log$ ). The examples shown in Figures 2 and 3 display "thin layer" responses in the SFL logs that could not be reconstructed from the lower-resolution ILD logs without additional information.

As a result, the authors decided to experiment with using the measured SFL as the input model to calculate a synthetic ILD log using the "Hardman Program." The iterative procedure used by the authors is outlined below, where ">" signifies the input (log) to the modeling scheme and " $\gg$ " signifies the output (log). 
In the first stage, we used the SFL log as the input model to calculate a synthetic ILD $\log$ (ILDcalc1), which we then compared with the ILD log measured downhole, and then we used the difference to correct the input model, shown as follows:

$$
\begin{gathered}
\text { SFL }>\text { Modeling }>\text { ILDcalc1, } \\
\text { Diff }=\text { ILD measured }- \text { ILDcalc1, } \\
\text { SFLcor }=\text { SFL + Diff. }
\end{gathered}
$$

The next stage involves validation, by comparing the ILD log (measured downhole) with that calculated from SFLcor:

$$
\begin{gathered}
\text { SFLcor }>\text { Modeling } \gg \text { ILDcalc2 } \\
\text { Err }=\text { ILD }- \text { ILDcalc2 }
\end{gathered}
$$

If $\mathrm{Err}=0$, then SFLcor provides an input to the "Hardman Program" that will yield a synthetic ILD log equal to that (ILD) measured downhole. In these circumstances, the authors propose that SFLcor is an estimation of the formation resistivity (Rt), which is better than either of the measured SFL and ILD logs. Figure 1 illustrates that the SFL "sees" more nearly the same volume as the ILD (compared to microresistivity pad-devices such as the FMS), and the resistivity contrast values are "close" to those seen by the ILD although the value may be different (as shown in Figs. 2 and 3).

The results of applying this scheme to the data in Figure 2 are shown in Figure 4. The largest positive correction in Figure 4 (point A at $213 \mathrm{mbsf}$ ) can be seen to coincide with the lowest resistivity in the SFL and the greatest fractional difference between the SFL and ILD resistivities. The authors contend that this is consistent with hole enlargement that would cause substantial errors in the estimation of formation resistivity from the SFL alone, while the estimation of the resistivity contrast between the layers would be severely reduced if the ILD log were used in isolation.

The correction applied to the SFL log is defined, in fractional form, by the authors as follows:

$$
\text { FraCorr }=(\text { SFLcor }- \text { SFL/SFL }) \text {, }
$$

and the fractional Error as:

$$
\text { FraErr }=(\text { ILDcalc2 }- \text { ILD }) / \text { ILD } .
$$

The fractional correction can be seen in Figure 4 to be almost 1.0 at 213 mbsf (point A) while the fractional error is almost zero at this depth.

The case of no correction of a thin layer can be seen at $207 \mathrm{mbsf}$ in Figure 4 (point B). The corrected $\log$ SFLcor in Figure 4 retains the thin bed boundary information of the SFL plus lower sensitivity of the ILD to borehole enlargement in this low resistivity sedimentary environment at Site 812 .

At depths greater than 141 mbsf drilling at Site 812 recovered samples that were described as being from a Miocene reef that had undergone subaerial exposure and freshwater diagenesis, plus dolomitization (Davies, McKenzie, Palmer-Julson, et al., 1991). They suggested that seawater may be currently moving through the upper $225 \mathrm{~m}$ of the platform and currently dolomitizing the calcium carbonate-rich sediments. These sediments below $141 \mathrm{mbsf}$ are described as intensely re-crystallized and lithified, with very high porosities (30\%-60\%) of moldic style, having dolomite as the dominant mineral (Davies, McKenzie, Palmer-Julson, et al., 1991). Therefore, the changes in resistivity seen in Figures 3 and 4 may due to variability introduced by diagenetically controlled pore morphologies and degree of cementation (Jackson et al., this volume) that may contain a record of fluctuations in Miocene sea level. Accurate, high-resolution electrical resistivity data will be required to aid in interpreting the sequence. The interval from 185 to $225 \mathrm{mbsf}$ contains many thin layer responses, some of which have been substantially corrected. Thus, corrected resistivities are necessary to further understand the diagenetic processes, rather than the unprocessed SFL log.
The corrected SFL log (SFLcor) is shown in Figure 5 for the interval 100 to $300 \mathrm{mbsf}$ at Site 815 . As described above, an expanded section occurs between 100 and 275 mbsf in which climatically controlled changes in sedimentation may be expected. Alternating light-to darker-colored intervals were identified in the core 60 to 100 $\mathrm{cm}$ thick and are thought to be related to changes in grain size and/or carbonate content (Davies, McKenzie, Palmer-Julson, et al., 1991). Shipboard interpretation of the downhole logs indicated the porosity, rather than cementation, was responsible for the cyclic "thin layer" responses seen in the interval from 100 to 275 mbsf at Site 815 . To assess the cyclic nature of the sedimentation from the resistivity logs, it is advisable to correct for poor borehole conditions, but to retain the resolution of the SFL because the layering seen in the core is in the range of 0.6 to $1.0 \mathrm{~m}$. Substantial corrections were required for the measured SFL log, as shown in Figure 5, and are likely to be due to preferential hole enlargement of particular layers, as seen in the core. For example, between 150 to $160 \mathrm{mbsf}$ in Figure 5 two zones are seen, each approximately $1 \mathrm{~m}$ thick, where substantial correction of the measured SFL has been done. These zones were identified as hole enlargement from the caliper log. The uncorrected resistivity logs would produce spurious results if used directly for spectral analysis with a view to identifying Milankovitch cyclicity. The fractional error in Figure 5 is generally less than 0.05 approximately, indicating that the ILD response, calculated from SFLcor, is almost equal to the measured ILD. The authors take this to indicate that SFLcor is a better estimate of the formation resistivity (Rt) than either the SFL or ILD logs (measured downhole).

The correction process is easily automated and can be extended to more than one iteration. The results of two iterations for the data in Figures 2 and 3 can be seen in Figure 6. Here, the fractional error is approximately halved with the addition of the extra iteration, with small changes to SFLcor.

\section{CONCLUSIONS}

An automatic interpretation procedure has been developed, for the low-resistivity environments encountered during Leg 133, that integrates the high resolution of the spherically focused $\log$ (SFL) with the deeper penetrating induction log (ILD), that is insensitive to both changes in borehole diameter and electric conduction within the borehole fluid.

Automatic procedures of this type can be applied to resistivity logs routinely without the input of substantial manpower. The corrected resistivities provide better data from which porosity and pore morphology can be estimated, (e.g., Jackson et al., this volume). Spectral analyses of expanded sections, in search of paleoclimatic indicators, will be enhanced by more accurate data that is not contaminated by hole enlargement effects.

The SFL log has been found to be a suitable starting point for modeling the deep induction $\log$ (ILD). The authors argue that FMS data would not be a good starting point for logs obtained in the vuggy carbonate environments experienced during Leg 133, as this data would not be representative of the formation away from the borehole wall. In addition, the FMS uses two electrode resistance measurements that are not designed to measure accurate absolute values directly, and considerable uncertainty would be introduced if FMS resistances are converted into electrical resistivities without the aid of additional microresistivity logs (at a resolution and depth of investigation comparable to the FMS). This additional information was not available during Leg 133.

The technique is applicable to ODP logging in low resistivity environments where horizontal layering predominates, and it is particularly suited to poor hole conditions. Further work will be required to assess anisotropic or dipping layer situations. The technique is not suitable for use in high resistivity hard-rock ODP environments, where galvanically coupled electrode arrays are favored for logging.

The SFL resistivity logs encountered during Leg 133 exhibit "thinlayer" responses, which indicate that these layers are too thin for the SFL 


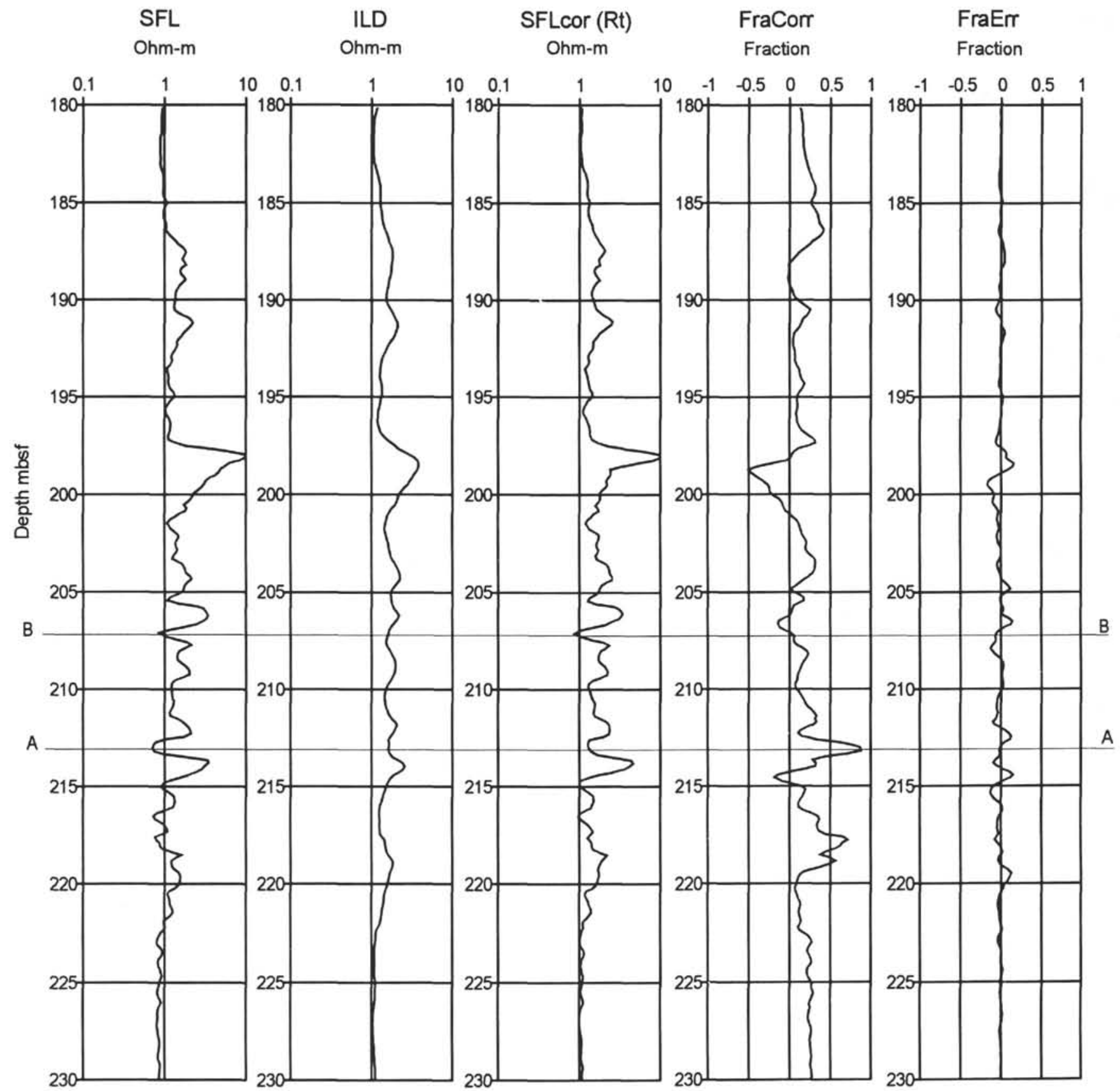

Figure 4. Site 812 logs showing the corrections and errors associated with the calculation of SFLcor (point A shows a thin bed response that is thought to be degraded by poor hole conditions).

resistivity tool to respond fully. Therefore, "thin-bed enhancement" of the corrected SFL log will provide more accurate absolute values for input into pore morphological and cyclicity analyses, both of which are relevant investigations of paleoclimate and changes in sea-level.

\section{ACKNOWLEDGMENTS}

This study is published with the permission of the Director BGS (NERC). This work has been supported by a Natural Environment Research Council, ODP Special Topic Grant.

\section{REFERENCES*}

Ajam, S.O., 1978. The dual guard/FoRxo logging device. Log Analyst, 19:28-36.

Archie, G.E., 1942. The electrical resistivity log as an aid in determining some reservoir characteristics. J. Pet. Tech., 5:1-8.

"Abbreviations for names of organizations and publication titles in ODP reference lists follow the style given in Chemical Abstracts Service Source Index (published by American Chemical Society). 
Davies, P.J., McKenzie, J.A., Palmer-Julson, A., et al., 1991. Proc. ODP, Init. Repts., 133: College Station, TX (Ocean Drilling Program).

Doll, H.G., 1949. Introduction to induction logging and application to logging of wells drilled with oil base mud. Pet. Trans, AIME, 264:148-162.

1950. The Microlog - a new electrical logging method for detailed determination of permeable beds. Trans. Am. Inst. Min., Metall. Pet. Eng., 189:155-164.

1951. The Laterolog: a new resistivity logging method with electrodes using automatic focussing system. Trans.

Am. Inst. Min., Metall. Pet. Eng., 198:17-32.

, 1953. The Microlaterolog. Trans. Am. Inst. Min., Metall. Pet. Eng., 198:17-32.

Ekstrom, M.P., Dahan, C.A., Chen, M.-Y., Lloyd, P.M., and Rossi, D.J., 1986. Formation imaging with microelectrical scanning arrays. Trans. SPWLA 27th Ann. Logging Symp., Pap. BB.

Hardman, R.H., and Shen, L.C., 1986. Theory of induction sonde in dipping beds. Geophysics, 51:800-809.

1987. Charts for correcting effects of formation dip and hole deviation on induction logs. Log Analyst, 28:349-356.

Jackson, P.D., 1976. Comments on "New results in resistivity well logging": Geophys. Prospect., 24:407-408.
1981. Focussed electrical resistivity arrays, some theoretical and practical experiments. Geophys. Prospect., 29:601-626.

Jarrard, R.D., and Arthur, M.A., 1989. Milankovitch paleoceanographic cycles in geophysical logs from ODP Leg 105, Labrador Sea and Baffin Bay. In Srivastava, S.P., Arthur, M.A., Clement, B., et al., Proc. ODP, Sci. Results, 105: College Station, TX (Ocean Drilling Program), 757-772.

Schlumberger, 1977. Log interpretation chart for induction log borehole correction. 6 FF40, Rcor- 4,45 .

1989. Using formation microscanner images. Tech. Rev., 37:16-40.

Schlumberger, C., Schlumberger, M., and Leonardon, E.G., 1934. Electric coring: a method of determining bottom-hole data by electrical measurement. Trans. AIME, 110:237-272.

Schuster, N.A., Baden, J.D., and Robbins, E.R., 1971. Applications of the ISF/Sonic tool to Gulf Coast formations. GCAGS Fall Mtg., New Orleans.

Standen, E., 1991. Tips for analyzing fractures on electrical well bore images. World Oil, April 1991:99-117.

Date of initial receipt: 13 March 1992

Date of acceptance: 23 March 1993

Ms 133SR-272 


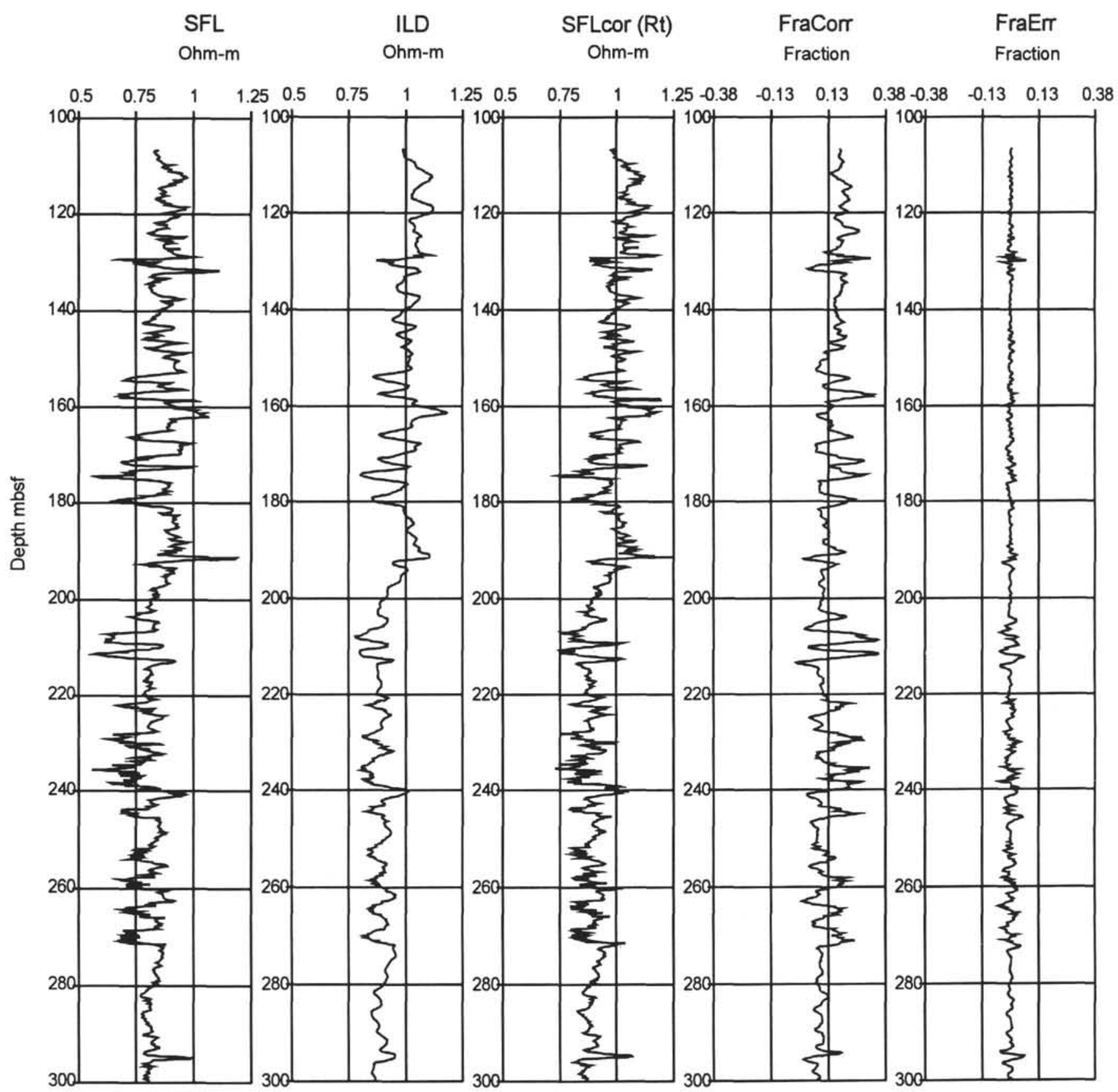

Figure 5. Site 815 logs showing the corrections and errors associated with the calculation of SFLcor (correction of the thin bed cyclic resistivity responses). 
P.D. JACKSON, R.D. JARRARD

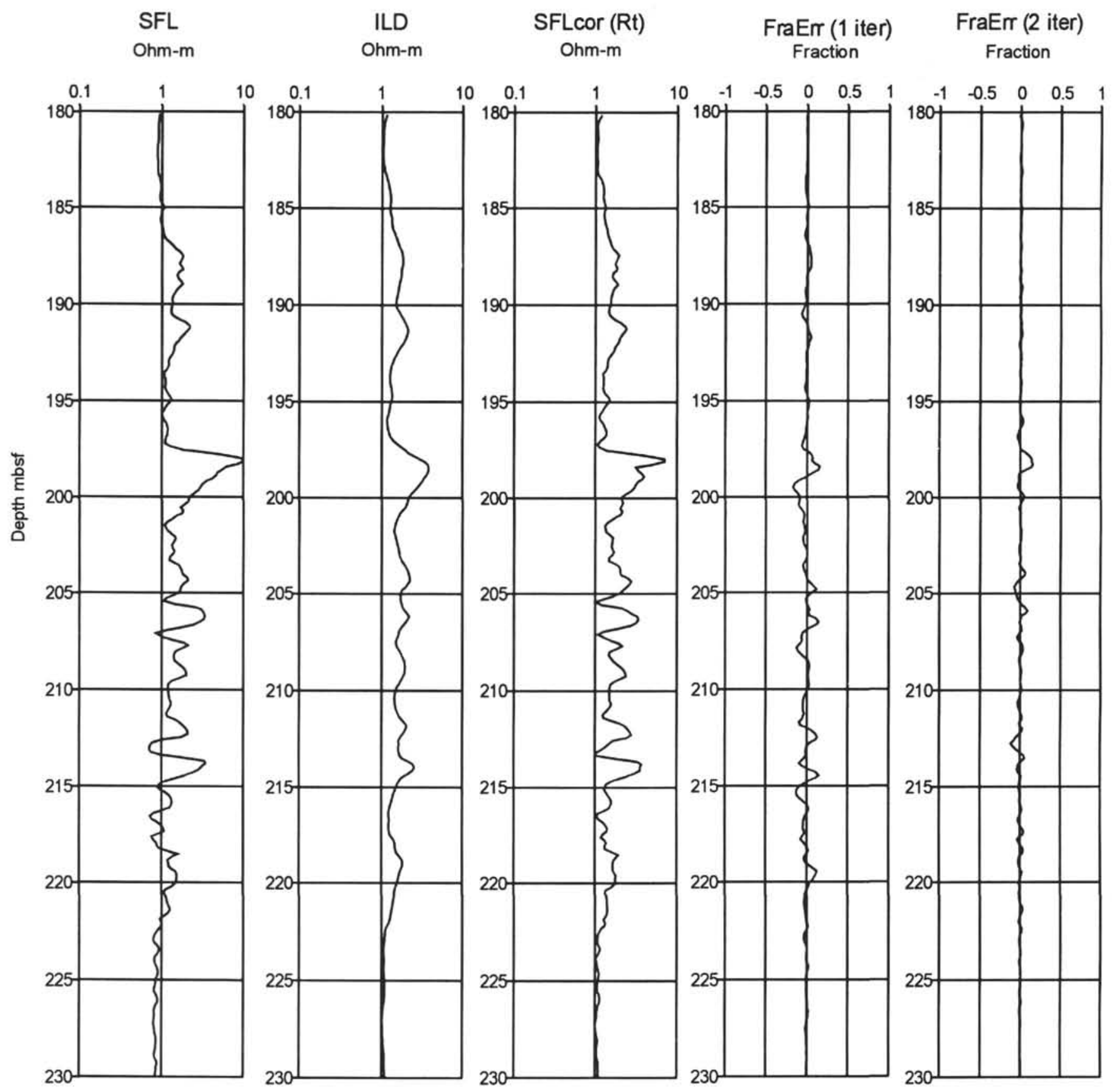

Figure 6. Two iterations of the correction procedure, on data from Site 812, reduces the fractional error (FraErr). 